\title{
Como desarmar o opressor? Reciclagem das emoções para ações estratégicas
}

\author{
How to Disarm the Oppressor? \\ Emotions Recycling for Strategic Actions
}

\section{¿Cómo desarmar al opresor? \\ Reciclaje de emociones para acciones estratégicas}

Lívia Moura *

Universidade Federal Fluminense, Brasil

https://doi.org/10.22409/poiesis.v20i34.38544

RESUMO: O presente artigo trata de ações artístico-pedagógicas como estratégias de transformação social. Propondo que a luta contra um opressor externo pode ser travada a partir de nossos mecanismos internos de autossabotagem, a "reciclagem das emoções" é o fio condutor desses processos, nos quais as emoções (agradáveis ou não) são utilizadas como matéria prima para essas transformações. A elaboração da própria energia vital em rituais (não religiosos) baseados em gestos banais, processos coletivos e coautorais se tornam um veículo para criar novas paisagens internas e externas. Serão utilizados como exemplo de "reciclagem das emoções" atividades pedagógicas e ações do coletivo VAV (Vendo Ações Virtuosas), baseadas em uma metodologia indicada pelas luzes do "semáforo das emoções".

PALAVRAS-CHAVE: arte contemporânea; pedagogia; reciclagem das emoções; energia vital

* Lívia Moura é bacharel em Artes Plásticas (UERJ) e mestra em Estudos Contemporâneos das Artes (UFF). E-mail: liviabmoura@gmail.com. 
ABSTRACT: This article deals with artistic-pedagogical actions as strategies of social transformation. Proposing that the fight against an external oppressor can be waged from the fight against our internal mechanisms of self-sabotage. The "recycling of emotions" is the guiding thread of these processes, where emotions (pleasant or not) are used as raw material for these transformations. The elaboration of one's own vital energy in non-religious rituals based on banal gestures, collective and co-authorial processes, become a vehicle for creating new inner and outer landscapes. It will be used as an example of "recycling of the emotions" pedagogical activities and actions of the collective VAV (Seeing or Selling Virtuous Actions) based on a methodology indicated by the "traffic lights of the emotions".

KEYWORDS: contemporary art; pedagogy; recycling of emotions; vital energy

RESUMEN: El presente artículo trata de acciones artístico-pedagógicas como estrategias de transformación social. Proponiendo que la lucha contra un opresor externo puede ser librada a partir de los nuestros mecanismos internos de autosabotaje. El "reciclaje de las emociones" es el hilo conductor de estos procesos, donde las emociones (agradables o no) se utilizan como materia prima para esas transformaciones. La elaboración de la propia energía vital en rituales (no religiosos) basados en gestos banales, procesos colectivos y coautorales, se convierten en un vehículo para crear nuevos paisajes internos y externos. Se utilizarán como ejemplo de reciclaje de las emociones actividades pedagógicas y acciones del colectivo VAV (Vendo Acciones Virtuosas) basadas en una metodología indicada por las luces del "semáforo de las emociones".

PALABRAS CLAVE: arte contemporáneo; pedagogía; reciclaje de las emociones; energía vital

Citação recomendada:

MOURA, Lívia. Como desarmar o opressor? Reciclagem das emoções para ações estratégicas. Poiésis, Niterói, v. 20, n. 34, p. 109-132, jul./dez. 2019.

[https://doi.org/10.22409/poiesis.v20i34.38544]

Lívia Moura, Como desarmar o opressor? Reciclagem das emoções para ações estratégicas. 


\section{Como desarmar o opressor? Reciclagem das emoções para ações estratégicas}

rasgar / soprar / estourar / queimar

/ lavar / embaralhar / desfilar / desatar nós / enlamear / modelar / quebrar / banhar / costurar / cozinhar / enterrar / desenterrar / plantar / desenhar / arrastar.
Quem é o opressor? Onde ele se encontra? Será que somos nós que o alimentamos? Será que ele tem pernas e braços dentro de nós? Como a luta contra um opressor externo pode ser travada a partir dos nossos mecanismos de autossabotagem? Como a arte e a educação podem ser o veículo para 


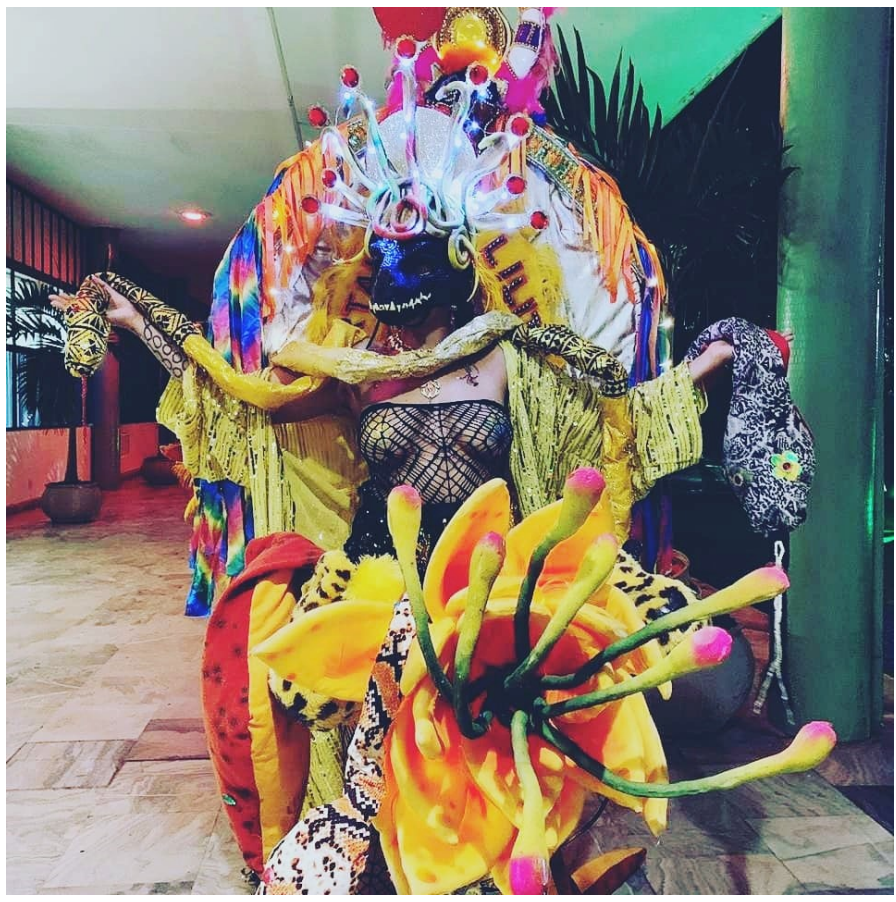

Fig. 1 - Bruna Abreu performando o Oráculo da Lilite no Triciclo Imantado da VAV como Portal da Lilite, Baile de carnaval Saronque, 2019. 
desarmar opressores? Será que o que acontece do lado de fora pode ser um espelho do precisamos trabalhar por dentro?

\section{Semáforo das emoções:}

Foi por conta dessas e tantas outras perguntas que comecei a desenvolver práticas que chamo de "reciclagem das emoções", como uma espécie de "ritual de iniciação humana" ressaltando a necessidade de reciclar nossas emoções para que elas se tornem matéria fértil para a regulação das nossas relações intra e interpessoais. Esses rituais consistem em dinâmicas com grupos para colocar em movimento nossa energia vital. São atos poéticos despidos de religiosidade, baseados em gestos mais ou menos cotidianos nos quais uma determinada intenção é colocada. Nossos sentimentos atuam nesse processo como um alarme para nos indicar o caminho a ser traçado e cada indivíduo é o responsável por encontrar suas próprias estratégias de ação e de reação.

Observando que nós, adultos, temos muita dificuldade em lidar com nossas emoções, decidi que seria importante desenvolver esses rituais de iniciação humana também com criança ${ }^{1}$. Em 2012 realizei meu primeiro laboratório na área de competências so- cioemocionais em uma escola pública do sul da Itália com alunos de 9 a 12 anos. Utilizo a sala de aula como um espaço de acontecimentos onde "ninguém educa ninguém, ninguém educa a si mesmo, os homens se educam entre si, mediados pelo mundo". (FREIRE, 1981, p. 79). As aulas se tornaram uma escultura social e afetiva, na qual o exercício de me comunicar com as crianças me permitia aprender com elas e com a criança que habita em mim.

Após alguns anos de experimentações, criei um "semáforo das emoções" ou "semáforo da energia vital" ${ }^{\prime 2}$ que se tornou a base pedagógica para o material didático "Raiz do Afeto", voltado para alunos do ensino fundamental I (BARROSO, 2018) ${ }^{3}$. A confecção desse material, todo baseado em rituais e atividades artísticas, me levou a organizar e a elaborar uma metodologia prática para processos que foram retroalimentando minhas ações com grupos sociais diversos.

O semáforo das emoções serve para nos lembrar que os sentimentos estão em trânsito e são apenas hóspedes. Passam as nuvens, as tempestades e os raios, mas por trás existe sempre um céu azul com um sol a brilhar ${ }^{4}$. Parto do princípio de que existe 
saúde dentro de todos nós e que cada um tem o seu próprio modo de se autorregular. Uma das principais funções desse semáforo é ressaltar que existe uma diferença entre emoção e comportamento; todos os sentimentos são aceitáveis, mas nem todas as condutas são aceitáveis. Não somos obrigados a nos identificar e a seguir impulsos violentos. Mas reprimir o impulso não faz com que ele desapareça. Portanto, o semáforo nos convida a direcionar essa energia para algo propositivo. E ninguém, além de nós mesmos, é o responsável por essa alquimia.

Para utilizar o semáforo, em primeiro lugar é necessário reconhecer nossos sentimentos com sinceridade e sem julgamentos. Dessa forma, a luz vermelha do semáforo acende. Para que a luz amarela acenda, proponho atividades para ajudar na reciclagem das emoções, oferecendo instrumentos e rituais para relaxar, extravasar e elaborar as emoções. Além de promover atividades para que os participantes encontrem suas próprias estratégias para isso. Nesse processo, o professor ou o artista, como Lygia Clark visionava nos anos 1960 , se tornam propositores:
Nós somos os propositores: nós somos o molde, cabe a você soprar dentro dele o sentido da nossa existência.

Nós somos os propositores: nossa proposição é 0 diálogo. Sós, não existimos. Estamos à sua mercê. Nós somos os propositores: enterramos a obra de arte como tal e chamamos você para que o pensamento viva através de sua ação.

Nós somos os propositores: não lhe propomos nem o passado nem o futuro, mas o agora. (CLARK, 1983)

Para acender a luz verde desenvolvemos juntos habilidades para resolver conflitos de maneira restaurativa e não violenta. Por fim, a luz violeta é um momento para refletir sobre o que foi aprendido com as emoções e oferecer os frutos dessa sabedoria para a comunidade.

Esse semáforo pode ser um instrumento para crianças, adultos, famílias, escolas, ações artísticas, movimentos sociais, círculos terapêuticos etc., no qual os participantes envolvidos reconhecem e reciclam suas emoções (luz vermelha e amarela do semáforo), mas também oferecem um resultado para um público externo, que podem ser imagens, diálogos, objetos e/ou ações (luz verde e violeta do semáforo). Vale ressaltar que em nossa,

Lívia Moura, Como desarmar o opressor? Reciclagem das emoções para ações estratégicas. 


\section{Semáforo das emoçōes}

Esse é o semáforo que utilizaremos para ajudar no trânsito das nossas emoções.

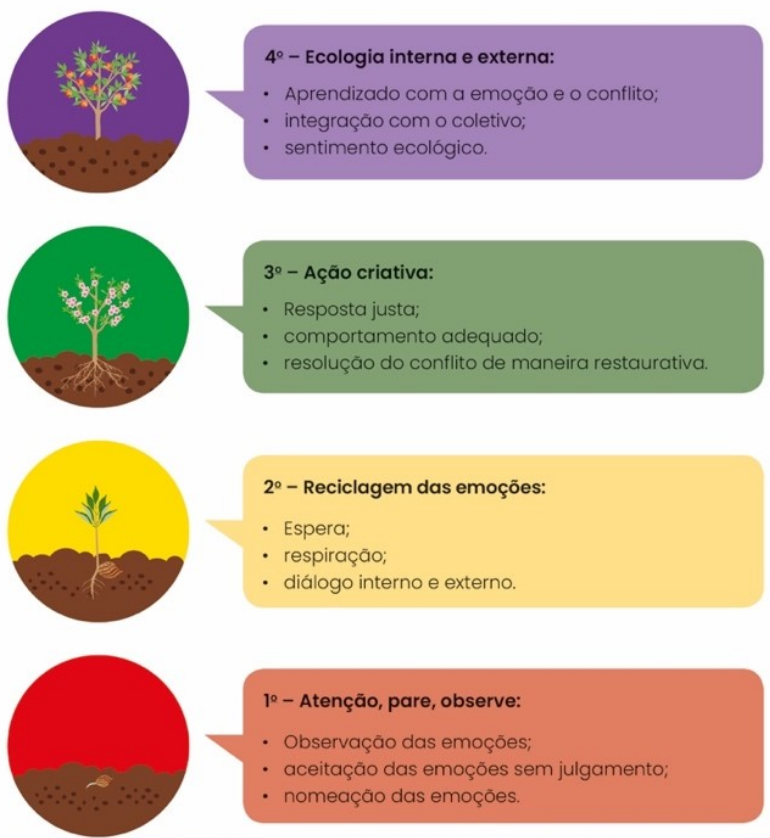

52

Fig. 2 - Lívia Barroso de Moura, Semáforo das Emoções, 2019.

(Fonte: BARROSO, Lívia. O segredo do céu azul - Raiz do Afeto [Ensino

Fundamental] Livro 2. Rio de Janeiro: Editora Raiz Educação, 2018, p. 52). 
quando surge uma emoção, todas as luzes do semáforo podem acender de uma só vez, ou demorarem anos para cada luz acender.

Sublimação e reciclagem das emoções:

\section{Se a perda da individualidade é, de certa maneira, imposta ao homem moderno, 0 artista lhe oferece uma revanche e a ocasião de encontrar-se. A0 mesmo tempo em que se dissolve no mundo, em que se funde no coletivo, 0 artista perde sua singu- laridade, seu poder expressivo. Ele se contenta em propor que os outros sejam eles mesmos, e que atinjam 0 estado singular de arte sem arte. (CLARK, 1983)}

Sentados em silêncio, quando os pensamentos deixam de ser um fluxo ininterrupto e começam a se espaçar no tempo, podemos observar que as emoções geram pensamentos em nossa mente e vice-versa ${ }^{5}$. Quando sentimos medo, automaticamente nossa mente produzirá pensamentos relacionados ao que estamos sentindo; é algo mecânico. O contrário também: se acreditamos em um discurso que incita a intolerância, esse discurso em nossa mente irá gerar sentimentos de ódio. Mas não estamos fadados a girar eternamente em uma espiral de pensamen- tos e sentimentos que nos levam cada vez mais ao fundo do poço. Temos a possibilidade de escolher o que fazer com nossos pensamentos e sentimentos.

Os pensamentos podem ser voluntários ou involuntários. Entretanto, a emoção é involuntária, não podemos controlar sua chegada. Podemos até promover um ambiente (incluindo os pensamentos) para que certas emoções floresçam, mas mesmo assim, emoções desagradáveis irão surgir sem que tenhamos controle. Para o neurocientista Jaak Panksepp, emoções como a raiva podem ser classificadas como "emoções defensivas", pois surgem como uma reação de defesa em relação a algo que nos atingiu. (PANKSEEP, 2004) Emoção vem do latim emovere - e de energia e movere de movimento -, ou seja, emoção é "energia em movimento". Sendo assim, as emoções podem ser vistas como um modo de impulsionar o sujeito a agir, a se defender, a fugir, a dançar, a se expandir, a contrair, a acariciar etc. As emoções não são "boas" ou "ruins", "negativas" ou "positivas"; agradáveis ou não, elas devem ser vistas como um impulso para nos colocar no movimento necessário. 
Para a medicina tradicional chinesa (MTC), raiva e criatividade são dois lados de uma mesma moeda. A raiva é representada pelo símbolo da madeira, relacionada com o fígado que tem um movimento de expansão. É também a partir desse movimento agressivo que surgiria a criatividade. Pensando dessa forma, a raiva gerada por alguma injustiça pode ser o motor para criarmos uma nova realidade em torno de nós. Já a tristeza, por exemplo, estaria relacionada ao pulmão, que tem um movimento de contração, de introspecção e, portanto, propício também ao desenvolvimento da sabedoria (MACIOCIA, 2007).

Do ponto de vista da MTC, existe um processo de autorregulação dos sentimentos no qual o medo excessivo, por exemplo, seria aplacado pelo intelecto, elemento terra - ligado ao estômago, ao pâncreas e ao baço - e que está associado também à organização. Ou seja, quando o medo se torna irracional ou excessivo é importante organizar o caos e, através do intelecto, voltar à terra e à razão. Já a raiva (expansão) excessiva só seria aplacada pela tristeza (contração). Se alguém está furioso, quebrando tudo, pode ser interrompido se alguém the avisar, por exemplo, que sua mãe morreu. (MACIOCIA, 2007)

Suely Rolnik afirma que a criação e o pensamento são impulsionados pelo desassossego da crise. Segundo a autora, o exercício lúdico, característico não só da produção do artista, mas de todos os que visionam novas possibilidades, é fundamental para a criação de outros mundos:

\section{Seja qual for o meio de expressão, pensa- mos/criamos porque algo de nossa vida cotidiana nos força a inventar novos possivivis que integrem ao mapa de sentido vigente, a mutação sensível que pede passagem. [...] É de dentro deste novo cenário que emergem as perguntas que se colocam para todos aqueles que pensam/criam - especial- mente, os artistas - no afã de traçar uma cartogra- fia do presente, de modo a identificar os pontos de asfixia do processo vital e fazer irromper aí a força de criação de outros mundos. (ROLNIK, 2006)}

Em momentos de crise aguda e "asfixia do processo vital" podemos abraçar a seguinte pergunta levantada pela autora: "Como reativar nos dias de hoje, em suas distintas situações, a potência política inerente à ação artística? Este poder de encarnar as mutações do sensível participando assim da 
reconfiguração dos contornos do mundo". (ROLNIK, 2006)

Como podemos observar, dependendo da maneira como afrontamos as crises e as emoções, elas podem gerar violência ou podem servir ao nosso crescimento pessoal e coletivo. A pergunta que se faz de acordo com a luz violeta do semáforo é: "o que esse sentimento ou conflito veio me ensinar e como posso oferecer essa sabedoria?". Trata-se de não asfixiar nosso processo vital e aprender a fazer uma compostagem das nossas emoções. Toda a bosta que recebemos (e sentimos dentro de nós) pode ser transformada em adubo fértil para uma nova vegetação emergir. Dessa forma, os conflitos não são vistos como problemas, mas como uma oportunidade para usar nossa potência criativa.

Mas não existe uma resposta ou um método pré-fabricado para lidar com asfixias e conflitos internos ou externos. O processo de reciclagem das emoções é algo que fazemos de maneira intuitiva e autodidata; cada indivíduo, em cada contexto, é o responsável pela ativação e autorregulação da energia vital. Certos instrumentos, discussões, trocas de experiências e práticas cole- tivas são fundamentais para aprofundar, potencializar e até mesmo viabilizar esses processos, utilizando o "poder regenerativo do fazer coletivo" (PLASTICA, 2015) para emancipar as subjetividades e os movimentos sociais. $O$ indivíduo não está separado de seu contexto e só iremos nos libertar das nossas amarras internas e externas se o fizermos coletivamente.

Até porque, o opressor externo tem seus súditos dentro de nós. Eles se tornaram íntimos porque penetraram sorrateiramente em nosso inconsciente coletivo. São os famosos autossabotadores, aquela voz que escutamos em nossa mente que diz: "você não é capaz", "nada vai dar certo", "a guerra e o sofrimento são a condição humana inevitável" etc. Para a psicanalista junguiana Clarissa Pinkola Estés, ele é representado pelo personagem Barba-azul ou "predador natural da psique" que, embora possa se apresentar simbolicamente de modo diferente nas psiques masculinas e femininas, é o inimigo ancestral e contemporâneo de ambos os sexos:

A história do Barba-azul fala desse carcereiro, 0 homem sinistro que habita a psique de todas as mulheres, o predador inato. [...] Para conter o pre- 
dador natural da psique, é necessário que as mu-

Iheres permaneçam de posse de todos os seus poderes instintivos. Alguns deles são 0 insight, a intuição, a resistência, a tenacidade no amor, a percepção aguçada, 0 al cance da sua visão, a audição apurada, os cantos sobre os mortos, a cura intuitiva e o cuidado com seu próprio fogo criativo. (ESTÉS, 1994, p. 63)

A maldade dos predadores pode se expandir, mas é limitada; em algum momento, algo irá impedir sua atuação, ou ela irá esgotar as reservas ou se autoesgotar. Já o amor pode se expandir e se ampliar infinitamente. $\mathrm{O}$ amor é a energia mais poderosa que existe e é justamente por isso que ele provoca tanto medo. O medo é a arma mais poderosa do opressor, pois nos faz vítimas voluntárias.

As dinâmicas baseadas na lógica da opressão se alimentam dos nossos monstros internos para sobreviver. São devoradoras famintas esperando que desçamos à sua condição para dialogar de igual para igual. A competição e a síndrome do predador permeiam todas as áreas sociais, desde a escola, o trabalho, a religião e até mesmo os momentos de lazer.
O amor é a salvação, mas, por ser tão óbvio e simples, faz com que nos empenhemos em construir inúmeros labirintos para obtê-lo. Como peixes nadando e se perguntando "onde fica o mar?" Mesmo não tendo consciência, todos nós, até nos atos mais tiranos, estamos buscando o amor em tudo o que fazemos. Substitua as palavras em itálico abaixo por "amor" para entender onde ele tem frequentemente se escondido:

- Acumular dinheiro, poder e terras

- Obter likes e followers

- Consumir objetos

- Excluir e oprimir os outros para que não falte nada para mim

Nosso corpo é um parque de diversões, um parque de diver(sasemo)ções. As paixões, os trens fantasmas e as montanhas russas que experimentamos podem ser tanto uma benção quanto uma maldição. Portanto, uso a metodologia do semáforo das emoções em minha vida pessoal, mas também nas ações desenvolvidas pela VAV (Vendo Ações Virtuosas). Criei a VAV em 2013 para ser um coletivo de arte que atue como uma plataforma de processos cocriativos. Ela é um guarda-chuva de projetos que partem de um ponto de vista feminista e incluem 


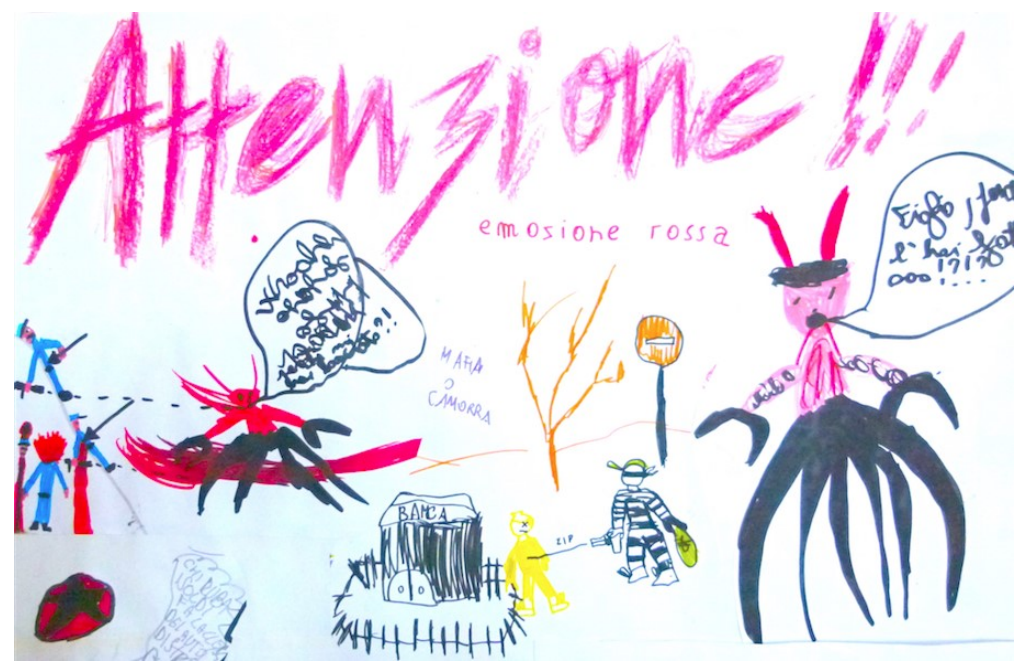

Fig. 3 - Alunos da Escola Estadual de Vietri Sul Mare

(imagem de arquivo de Lívia Moura do Laboratório de Reciclagem das Emoções, semáforo vermelho, Itália, 2012). 
processos pedagógicos, intervenções urbanas, rituais, publicações e atuações em instituições de arte. O Triciclo Imantado é nossa instituição de arte, um centro magnético de ações e irradiações que se transforma de acordo com as vontades coletivas. PromoVemos e Vendemos ações virtuosas na bolsa de valores éticos para o desenvolvimento sustentável da economia da energia vital. ${ }^{6}$

O princípio de minhas proposições pedagógicas com crianças e das ações da VAV com diferentes grupos sociais é o mesmo: o medo, a raiva, a dor, a inadequação, as cicatrizes e a inquietude se tornam a força para movimentos de emancipação, nos quais se cria um paralelo entre o que acontece por fora e o que acontece por dentro. A reciclagem das emoções nesse contexto é um processo sublimatório. Nele, o sujeito se "desterritorializa" (ROLNIK, 2000), formando um campo de batalhas íntimas ou, mais precisamente, essa intercessão entre íntimo e exterior que Lacan chama de "êxtimo". (RIVERA, 2013)

No Manifesto Antropofágico, Andrade dialoga com Freud e, especificamente, sobre o conceito de sublimação, no seguinte trecho:
[...] Porém, só as puras elites conseguiram realizar a antropofagia carnal, que traz em si o mais alto sentido da vida e evita todos os males identificados por Freud, males catequistas. 0 que se dá não é uma sublimação do instinto sexual. É a escala termométrica do instinto antropofágico. De carnal, ele se torna eletivo e cria a amizade. Afetivo, 0 amor. Especulativo, a ciência. Desvia-se e transfere-se. [...] Contra as sublimações antagônicas. Trazidas nas caravelas. (ANDRADE, 1928)

Em contraposição à sublimação freudiana (na qual se desvia a pulsão libidinal para algo culturalmente produtivo), na antropofagia do instinto carnal se criariam novas conexões afetivas com o outro: a amizade, o amor e a ciência. Se desviando e transferindo-se, a sublimação aqui se daria nesse espírito que "recusa-se a conceber o espírito sem o corpo. O antropomorfismo". (ANDRADE, 1928) Neste ponto de vista, a antropofagia brasileira é vista como um exemplo poderoso de devir pela sublimação como um processo coletivo. Em um processo de transmutação da bosta ao adubo, onde "o samba é pai do prazer, o samba é fiIho da dor. O grande poder transformador". (VELOSO, 1993) 
Rituais de Iniciação Humana:

Ritual para o fim do milênio, quando surfar na desterritorialização tornou-se indispensável para constituir um abrigo na nova paisagem em que vivemos, com suas velozes mutações tecnológicas e sua globalização, que expõem o corpo vibrátil a toda espécie de outro, e tudo mistura na subjetividade de cada habitante do planeta. (ROLNIK, 2000)

Desde Hélio Oiticica e Lygia Clark, várias gerações de artistas investem em uma virada das práticas artísticas para horizontes de conectividade, colaboração e convivência humana. HO, através do seu interesse nas práticas relacionais, também defendia que os sentidos dariam bases para novas transformações humanas. A partir da experiência neoconcreta e seu Programa ParangoléAmbiental, $\mathrm{HO}$ investiu crescentemente na fragmentação e no fim do objeto, assumindo os sentidos como bases para novas transformações humanas. Da mesma forma, Lygia Clark rompe com a ortodoxia do objeto da arte concreta, a começar pela linha orgânica, na construção do self e estruturas relacionais.

Seguindo essa inflexão, a VAV parte para proposições artísticas que ativam camadas de consciências - centradas no corpo, vozes e vibrações - que compõem um "individuum"; quando se reconhece não mais separado do entorno. Nesta abordagem, se configura uma visão do indivíduo como um campo no qual são travadas inúmeras bataIhas emocionais e psicossociais, que se ampliam infinitamente como rendas de sensibilidades expandidas transtemporais, universais, planetárias e cósmicas.

Os três eixos principais de atuação da VAV são: 1. economia da energia vital, 2 . alfabetização emocional e 3 . resgates e reinvenções do imaginário na descolonização do patriarcado. Eles estão interligados por uma virada no sentido da arte em promover plataformas de vivências pela regeneração das relações de parceria e cooperação, em contraposição às relações capitalistas patriarcais de dominação e de opressão que regem o mundo atual. Partimos do princípio de que conflitos surgem de sentimentos/pensamentos mal direcionados, nos tornando reféns do nosso próprio veneno, conduzindo ao desequilíbrio e ao bloqueio da energia vital, e que, portanto, as primeiras batalhas contra um sistema opressor são travadas dentro de nós mesmos. 


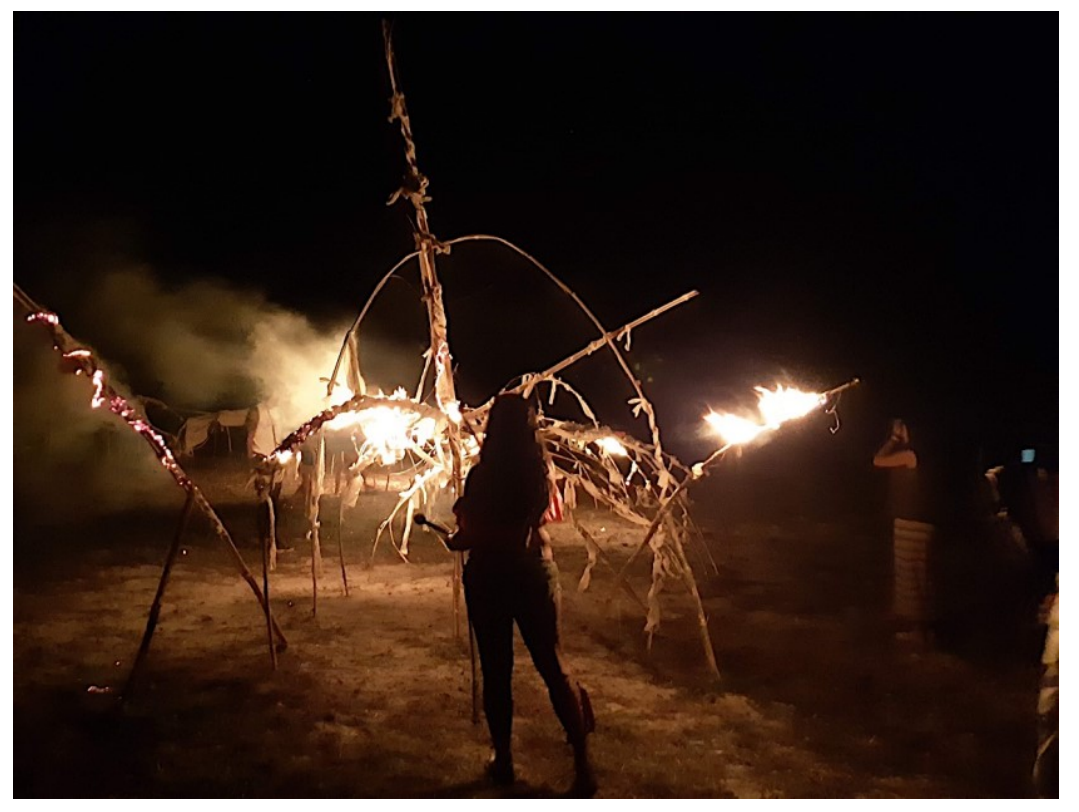

Fig. 4 - Vendo Ações Virtuosas, Seu poder pessoal reside nos seus medos mais profundos, 2019. Último ritual do "Portal da Lilite", queima coletiva da land art, bambú, tecidos e crânios de javali, 30 m, Rio Grande do Norte. 
Tanto HO quanto LC traziam para seus trabalhos e reflexões as inquietações existenciais que ecoavam batalhas íntimas e mudanças nos modos de criação e percepção de afetos. Partindo desse mesmo interesse no desenvolvimento de uma consciência individual expandida, urge a vontade de me aprofundar em estudos e práticas artísticas que investem na interconectividade através de processos de "Alfabetização Emocional"7. Essas ações estão, portanto, ligadas direta ou indiretamente ao que Espinosa chamaria de uma ética dos afetos (ESPINOSA, 1980). Como desdobras para uma pesquisa ampliada das práticas artísticas, são tecidas coletivamente germinações por mútuas afecções e afetos, oferecendo espaços de encontros e modos de ser e estar juntos mais plenos e conectados, como corpos de múltiplos corpos que compõem o planeta. Remetendo a Espinosa:

0 corpo humano é composto de um grande número de indivíduos (de natureza diversa), cada um dos quais é também muito composto. [...]

0 corpo tem necessidade, para sua conservação, de muitos outros corpos, pelos quais é como que continuamente regenerado. (ESPINOSA, 1992, p. 219)
As proposições da VAV são pautadas pela experiência e intuição, de acordo com o ambiente e o interesse de múltiplos corpos, defendendo o que Espinosa chamaria de uma ciência intuitiva de afetos, nas relações com o ambiente, promovendo encontros alegres que gerem o despertar de vontades e potência de agir (ESPINOSA, 1980). ${ }^{8}$

Suely Rolnik escreve sobre a importância do "corpo vibrátil" na obra de Lygia Clark, em um percurso que vai do objeto ao sujeito, no qual a obra de LC passaria a atuar em um campo invisível, "na pura sensação das emanações dos corpos dos parceiros de experiência, captadas pelo corpo vibrátil de cada um" (ROLNIK, 2000), radicalizando a participação do espectador ao propor rituais coletivos que culminariam em sua última fase, mais intimista: a "Estruturação do self". Segundo Rolnik:

\footnotetext{
Lygia insiste que suas obras propõem um "rito sem mito". Com efeito, não é um mito transferente, exterior ao homem, o que será registrado, mas a potência de criação permanente do sentido de si e do mundo, que todo homem, enquanto ser vivo, possui virtualmente: é essa potência que será reativada. (ROLNIK, 2000)
} 
Nesses processos artísticos nos quais se promove a "potência de criação do sentido de si e do mundo", pode se produzir um rasgo no momento presente e um afloramento da consciência de que "não estamos na paisagem: somos a paisagem". (DELEU-ZE; GUATTARI, 1992) Essa experiência não seria a revelação de um objeto exterior a nós, mas um abrir-se do sujeito a si mesmo em seu estado constitutivo de "Eu-fora". Nas palavras de Cézanne, essa descentralização é descrita como "o homem ausente, mas inteiro na paisagem. [...] Há um minuto do mundo que passa", não nos conservaremos sem "nos transformarmos nele". (CÉZANNE apud DELEUZE; GUATTARI, 1992)

O que busco nos rituais de iniciação humana da VAV é justamente que possamos desenvolver a consciência e a capacidade de se reciclar reciclando a paisagem e viceversa ao percebermos que o que acontece no mundo é um espelho do que precisamos trabalhar dentro de nós. Se vemos catástrofes e fascistas no poder é porque estamos sendo convocados a olhar para os nossos desastres e tiranos internos. Lygia Clark. quando afirma "Eu sou o outro" (CLARK, 2006) no seu texto $A$ supressão do objeto, descreve, de certa forma, essa transmissão enigmática entre sujeito e paisagem:

0 engolir 0 espaço exterior para abrindo os pulmões num grito, espaço esse identificado por mim com o que chamei há anos de "vazio pleno", em que a poética ainda era transparente. Religamento do espaço metafísico com o imanente. Já nada invento só as invenções nascem [...] numa troca comum de diálogo, sendo isso que mais colado à vida consegui propor. Divido a proposição e aceito a invenção do outro. Grande instinto de morte colado à grande vitalidade. (CLARK, 2006)

Esses rituais que proponho são próximos também aos atos psicomágicos que Alejandro Jodorowski receita para os seus pacientes (JODOROWSKI, 2009). Jodorowski afirma que não faz diferença para nosso corpo se estamos sonhando ou se estamos acordados. Dentro de uma situação de terror, o corpo irá sentir medo da mesma maneira, seja em um sonho ou em uma situação real. Portanto, para conversar com o inconsciente precisamos usar a mesma linguagem dele, criando atos poéticos e oníricos que possam resolver equações profundas de nossa vida.

Esse estado também dialoga com princípios zen budistas, nos quais se afirma que ges- 
tos cotidianos podem ter o poder (simbólico e concreto) de plasmar a paisagem externa e interna ao mesmo tempo, em uma aposta de que a imersão no momento presente provocaria uma descentralização do sujeito em relação ao outro e à paisagem. Arrumar a casa com a presença plena seria em si se arrumar internamente, assim como limpar, cozinhar e assim por diante.

Após anos frequentando e morando em mosteiros zens (entre 2008 e 2012), adotei esse princípio na minha prática artística para explorar processos coautorais e coletivos com a possibilidade de que gestos cotidianos pudessem se transformar em rituais de iniciação humana, como rasgar, soprar, estourar, queimar, lavar, embaralhar, desfilar, desatar nós, enlamear, modelar, quebrar, banhar, costurar, cozinhar, enterrar, desenterrar, plantar, desenhar, arrastar.

Todos esses gestos estão presentes em alguma ação da VAV, e foram transformados em atos êxtimos, onde quebrar tem ao mesmo tempo o poder de "quebrar algo dentro de si" ou "quebrar alguma estrutura social"; cozinhar, "se cozinhar ou cozinhar alguma situação"; plantar, "plantar em si algo ou plantar algo no planeta", e assim por diante, criando dessa forma rituais de iniciação humana poéticos, isentos de religiosidade e que não irão necessariamente se repetir daquela forma, na qual um ato cotidiano se torna um ato êxtimo e psicomágico, que reverbera dentro de um sujeito expandido na paisagem.

Tanto as ações da VAV em espaços públicos quanto as atividades em salas de aula atuam como um agente aglutinador, uma escola "pública de arte"9, onde ocorrem encontros, interações e trocas de saberes. Os participantes se tornam autores de novas paisagens internas e externas, em um ambiente que acolhe e apoia as propostas e criações coletivas se valendo da escuta, da incerteza e do experimentalismo como método, substituindo uma suposta universalidade do saber por "pluriversalidades". (MIGNOLO, 2010)10 O exercício da criatividade e da arte não é atribuído a poucos experts e todos são convocados a serem cocriadores de nossa existência interligada. Não estamos produzindo possíveis leituras do mundo, mas criando novos mundos. Nas palavras de LC:

0 artista se dissolve no mundo. Seu espírito se funde com o coletivo, permanecendo ele mesmo. Pela

Lívia Moura, Como desarmar o opressor? Reciclagem das emoções para ações estratégicas. 
primeira vez, ao invés de interpretar um fato existente no mundo, muda-se esse mesmo mundo por uma ação direta. (CLARK, 1983)

Para Amit Goswami, a tecnologia da energia vital será a nova fronteira tecnológica do século XXI (GOSWAMI, 2015). Ele está se referindo, em seu livro intitulado Economia da consciência, às "tecnologias sutis" que precisaríamos desenvolver como ser humano para manter viva a energia vital pessoal e planetária, dentre elas o autoconhecimento, a intuição, a criatividade, a expansão da consciência e a elaboração das emoções. Precisaríamos desenvolver essas tecnologias desde pequenos para que os mecanismos de manipulação não nos mantenham aprisionados.

Aprender a reciclar e sublimar as emoções pode ser um importante ponto de partida para lidar contra a tirania, qualquer que seja. Como um alquimista da própria energia vital, o sujeito criativo transformaria as crises no motor para as transformações necessárias. Estimular a todos a criar seus próprios rituais experimentais de reciclagem das emoções se impõe, portanto, como uma proposta artístico-pedagógica da $\mathrm{VAV}$, construindo uma ponte entre as trans- formações sociais com uma revolução interna e subjetiva, na qual sujeito e paisagem se misturam e temos em nossas mãos a escolha de utilizar os sentimentos (agradáveis ou não) como o motor para participar de uma transição planetária. Expandindo essa consciência da paisagem para uma consciência cósmica, convocamos seres de todas as dimensões e de todas as crenças para ajudar nesse processo de transição. Contamos também com a ajuda do leitor deste artigo, para que possa criar seus próprios rituais de reciclagem das emoções individuais e coletivos.

Portanto, segue uma proposta para de um exercício experimental de um ritual de iniciação humana, um ato psicomágico ${ }^{11}$ de reciclagem emocional. Ele pode ser feito com sua família ou em seu trabalho, para si ou como um ato emergencial para o planeta, tendo como base as etapas do semáforo das emoções ${ }^{12}$ :

a) Pegue o jornal e leia as piores notícias em voz alta (luz vermelha).

b) Desenhe ou escreva sobre um papel os seus maiores monstros, medos, raivas, frustrações e inquietações (luz vermelha). 
c) Faça a respiração de um "guerreiro" com os pés bem plantados no chão dando socos no ar e gritando "rá!" a cada soco. Deixe que o som saia do abdômen e faça quantas respirações achar necessário. Isso poderá te dar coragem para enfrentar os monstros (luz amarela).

d) Agora rasgue com vontade o desenho até virar picadinho. Se quiser, você pode gritar enquanto rasga. Mas se a sua raiva for do tipo "fria", você pode também usar um triturador e colocar em silêncio os jornais e papéis desenhados para serem devidamente triturados (luz amarela).

e) Jogue tudo no liquidificador com um pouco de água e cola. Se quiser dê uivos, gritos ou xingue à vontade dentro do liquidificador. Você terá, dessa forma, uma boa massa para fazer papel machê (luz amarela).

f) Faça uma meditação ou relaxamento (luz amarela).

g) Modele na massa o que você quer que seus monstros se transformem. $\mathrm{O}$ importante não é tanto o resultado final da "escultura", mas a intenção que você coloca nela (luz verde). h) Acrescente algumas sementes à massa de papel machê e deixe-as brotar em um jardim intitulado "Cidade das Emoções Recicladas" (luz violeta).

Tecnólogos da energia vital ${ }^{13}$, uni-vos! 


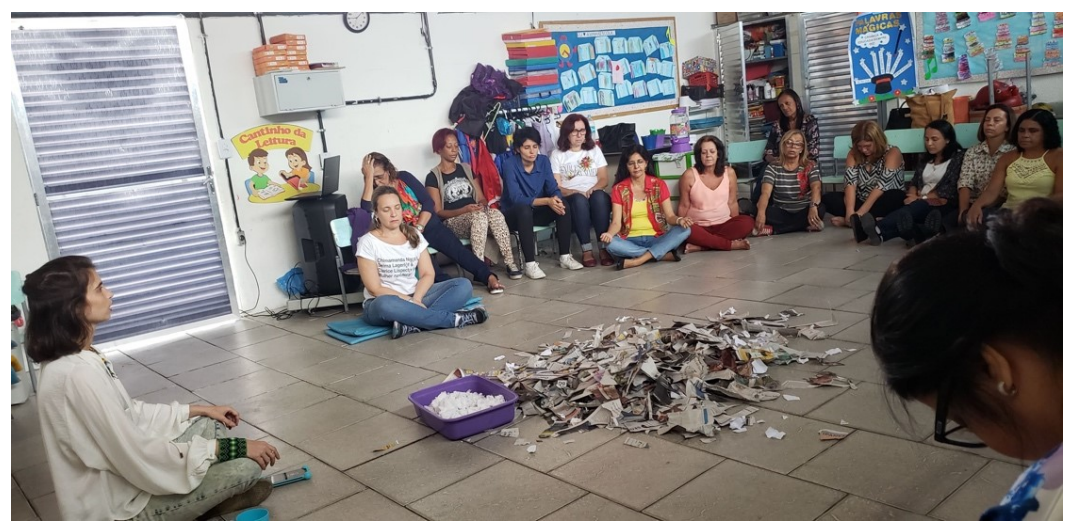

Fig. 5 - Vendo Ações Virtuosas, Reciclagem das Emoções, Lívia Moura, professoras e funcionárias da Escola Municipal Thaumaturgo de Azevedo, Rio de Janeiro, 2019. 


\section{Notas}

1 Desde 2008 investigo sobre o funcionamento da mente e das emoções através de práticas holísticas, sobretudo as práticas e os estudos zen budistas. Muito dos projetos que faço até hoje é fruto dessas investigações, que partem inicialmente de um interesse pessoal e não profissional.

2 O semáforo das emoções (presente na ilustração a seguir) foi baseado num semáforo descrito no livro $\mathrm{Co}$ mo lidar com as emoções destrutivas. (GOLEMANN, LAMA, 2003) Originalmente, ele tinha as 3 cores normais de um semáforo de trânsito. Mas, conversando com um amigo artista, Bernardo Ramalho, decidi inverter a ordem das cores do semáforo. E reelaborei o conceito dele para que as etapas coincidissem com as cores dos chacras, acrescentando também a cor violeta.

3 Este material está sendo pilotado no ano de 2019 por 1.014 crianças entre o Rio de Janeiro e Porto Alegre, um processo que também inclui a formação dos professores que utilizam o material. Por questões logísticas, em tempos de fortes polarizações, decidi assumir o nome Lívia Barroso para as ações pedagógicas e Lívia Moura para as ações no campo artístico. No desejo de que em algum momento essas divisões não sejam mais necessárias e possamos ver as práticas artísticas e pedagógicas realmente integradas, sem preconceitos de ambas as partes.

${ }^{4}$ Essa metáfora faz parte de ensinamentos zen budistas e se tornou um paradigma de todo o percurso proposto pelo material didático. E se tornou uma música chamada "Segredo do céu azul", composição feita pela minha mãe Rosa Barroso (é possível ouvir a música no app spotify).

${ }^{5}$ Esse trecho descreve experiências provadas durante a prática do zazen, a meditação sentada no zen budismo.

6 Para conhecer um pouco das nossas ações acesse o nosso instagram: @vendoacoesvirtuosas.

7 Alfabetização Emocional foi um termo que encontrei também no livro Como lidar com as emoç̃̃es destrutivas (GOLEMAN e LAMA, 2003). Achei esse termo curioso pois parecia conter em si uma ironia, uma promessa de algo intangível, inacabável e subjetivo. Ao mesmo tempo a palavra "alfabetização", assim como "reciclagem", são muito conhecidas e adoradas no campo pe- dagógico, servindo como ótimas iscas para operar desvios necessários.

${ }^{8}$ Essas conceituações éticas de Espinosa também estão presentes nas viradas de Lygia Clark - como os objetos relacionais, as arquiteturas orgânicas, a Cabeça Coletiva e tantos outros- que se dedica ao final de sua vida a uma prática experimental terapêutica.

9 Termo utilizado por Luiz Guilherme Vergara e Jessica Gogan do Instituto Mesa (www.institutomesa.org).

10 "Pluriversalidades" é um termo utilizado por Walter Mignolo para indicar as diversas possibilidades de fontes de conhecimento, que se opõem a uma suposta universalidade eurocêntrica e etnocêntrica do conhecimento (MIGNOLO, 2010).

11 Esse não pode ser considerado exatamente um ato psicomágico nos termos de Jodorowski, pois esses originalmente eram únicos e intransferíveis.

12 Esse é um exemplo de um ritual da VAV desenvolvido no Ping festival (RJ, 2017) com cerca de 200 pessoas e em encontros de formação de professores. Ele está presente também no material didático "Raiz do Afeto" para que os alunos façam em sala de aula. E já foi praticado algumas vezes aqui em casa com os meus filhos, em momentos de crises de medo.

13 "Tecnólogos da energia vital" é um termo criado por Amit Goswami e está presente no seu livro intitulado Economia da consciência. (GOSWAMI, 2015) 


\section{Referências}

ANDRADE, Oswald. Manifesto Antropofágico. Revista de Antropofagia, ano I, n. 1, maio de 1928.

BARROSO, Lívia. O segredo do céu azul Raiz do Afeto (Ensino Fundamental) Livro 2. Rio de Janeiro: Editora Raiz Educação, 2018.

CERVETTO, Renata; LOPEZ, Miguel A. (Org.). Agite antes de usar. São Paulo: Edições Sesc, 2018.

CLARK, Ligia. A supressão do objeto. In FERREIRA Glória; COTRIM, Cecília (Org.). Escritos de Artistas. Rio de Janeiro: Zahar, 2006.

CLARK, Lygia. Cópia do Livro-Obra. 1964 (publicado em 1983 por Luciano Figueiredo e Ana Maria Araújo, em uma edição limitada de 24 exemplares).

DELEUZE, Gilles; GUATTARI, Felix. Percepto, afecto e conceito. In $O$ que é filosofia? São Paulo: Ed. 34, 1992.

ESPINOZA, Baruch. ÉTICA demostrada según el ordem geométrico. Madrid: Ed Nacional, 1980.

ESPINOSA, Baruch. Ética: introdução e notas Joaquim Carvalho. Lisboa: Relógio D’água. 1992.

ESTÉS, Clarissa Pinkola. Mulheres que correm com lobos. Rio de Janeiro: Rocco, 1994.
FREIRE, Paulo. Pedagogia do oprimido. Rio de Janeiro; Ed. Paz e Terra, 1971.

GOLEMANN, Daniel; LAMA, Dalai. Como lidar com as emoções destrutivas. Rio de Janeiro: Elsevier, 2003.

GOSWAMI, Amit. Economia da consciência. São Paulo: Aleph, 2015.

JODOROWSKI, Alejandro. Psicomagia. São Paulo: Devir, 2009.

KROPOTKIN, Piotr. Ajuda mútua, um fator de evolução. São Sebastião: Ed. Senhora, 2009.

MACIOCIA, Giovanni. Os fundamentos da Medicina Chinesa. Rio de Janeiro: Ed. Roca, 2007.

MIGNOLO, Walter. Desobediencia Epistémica: Retórica de la modernidad, lógica de la colonialidad y gramática de la descolonialidad (Colección Razón Política). Buenos Aires: Ediciones del Signo, 2010.

NANCY, Jean Luc. Corpo, Fora. Rio de Janeiro: 7 Letras, 2015.

PANKSEPP, Jaak. Affective Neuroscience: The Foundations of Human and Animal Emotions. Oxford: Oxford University Press, 2004.

PLASTICA, Ala. Iniciativa Biorregional: A redefinição dos espaços de criação e ação. In GOGAN, Jessica; VERGARA, Luiz Guilherme (Org.). Espaços poéticos= linguagens éticas: diversas práticas na América Latina. Revista MESA (Ed. Azougue), n. 2, p. 56-61, abril 2015. 
RIVERA, Tania. O avesso do imaginário. São Paulo: Ed. Cosac Naify, 2013.

ROLNIK, Suely. O corpo vibrátil de Lygia Clark, 2000. Disponível em http://www1. folha.uol.com.br/fsp/mais/fs3004200006. htm. Acesso em 18/08/2016.

ROLNIK, Suely. Geopolítica da cafetinagem, ano 2006. Disponível em http://eipcp.net/ transversal/1106/rolnik/pt. Acesso em 20/03/2018.

VELOSO, Caetano. Desde que o samba é samba. In GIL, Gilberto; VELOSO, Caetano. Tropicália 2 (álbum), 1993. 